\title{
Р.И. Капелюшников
}

ИМЭМО им. Е.М. Примакова, РАН;

Центр трудовых исследований (ЦеТИ) НИУ ВШЭ, Москва

\section{А.В. Шарунина \\ Центр трудовых исследований (ЦеТИ) НИУ ВШЭ, Москва \\ Потребление культурных благ в России: что говорят опросные данные?}

Аннотация. В работе на основе представительных обследований домохозяйств анализируются особенности потребления культурных благ в России. Источниками эмпирических данных служат «Российский мониторинг экономического положения и здоровья населения» (РМЭЗ-ВШЭ) за 2000-2018 гг. и «Комплексное наблюдение условий жизни населения» (КОУЖ) Росстата за 2011-2018 гг. Анализ показывает, что в настоящее время в России примерно каждое второе домохозяйство и примерно каждый второй индивид в течение года потребляют те или иные культурные блага. Постоянная аудитория составляет примерно пятую часть общего числа посетителей. Доля расходов, направляемых на приобретение культурных благ, достигает 2,5\% месячного бюджета домохозяйств. По мере быстрого роста доходов в 2000-2018 гг. спрос на культурные блага повышался. Прослеживается четкая эмпирическая закономерность: чем выше доход домохозяйств или индивидов, тем активнее они ведут себя в сфере потребления культурных благ. Полученные результаты позволяют сделать вывод о существовании в российских условиях достаточно банального, но эффективного способа стимулирования спроса на культурные блага, и это - ускорение темпов экономического роста.

Ключевые слова: потребление, культурные блага, доход, Россия.

Классификация JEL: D12, D31, Z11, Z18.

DOI: $10.31737 / 2221-2264-2020-47-3-11$

Настоящий текст представляет собой часть большого исследовательского проекта, посвященного паттернам потребления культурных благ в России. Анализ данного круга вопросов достаточно широко представлен в российской социологической и экономической литературе. Однако до сих пор объектами изучения чаще всего становились целевые аудитории тех или иных видов искусства (зрители театров, слушатели классической музыки и т.д.). Отсюда - преобладание эмпирических оценок ad hoc, лишенных строгой теоретической базы и несопоставимых из-за этого с аналогичными оценками для обычных потребительских благ.

Долгое время примерно так же обстояло дело и в зарубежных исследованиях по экономике культуры (см. содержательные обзоры литературы по этой теме (Автономов, 2013; Бузанакова, Ожегов, 2016)). Ситуация стала меняться лишь в последние 10-15 лет, когда у исследователей появилась возможность работать с большими выборками, репрезен- тирующими все население и, следовательно, включающими как тех, кто предъявляет спрос на культурные блага, так и тех, кто его не предъявляет (Borgonovi, 2004; Pawlowski, Breuer, 2012; Muñiz, Rodriguez, Suarez, 2014; Yoon, Heo, 2015).

Наша работа ориентирована именно на этот новейший поток исследований. Насколько нам известно, в отечественной экономической литературе она является первой, где особенности потребления культурных благ в российских условиях анализируются на микроуровне с привлечением данных представительных обследований домохозяйств. Для этого используются два авторитетных источника. Во-первых, «Российский мониторинг экономического положения и здоровья населения» (РМЭЗ-ВШЭ) за 2000-2018 гг. Во-вторых, «Комплексное наблюдение условий жизни населения» (КОУЖ) Росстата за 2011-2018 гг.

Еще одно ограничение предшествующих исследований было связано с тем, что из-за отсутствия информации они обходили сторо-

\footnotetext{
${ }^{1}$ Авторы выражают глубокую признательность А.Я. Рубинштейну за поддержку и ценные советы.
} 
ной такой важнейший фактор формирования спроса, как доход. Мы попытались восполнить и этот пробел, поскольку вопрос о связи потребления культурных благ с дифференциацией доходов - один из наиболее фундаментальных для экономики культуры.

\section{Эмпирическая база}

Один из разделов семейного вопросника РМЭЗ-ВШЭ, посвященный расходам домохозяйств, содержит вопрос: «Тратила ли ваша семья в течение последних 30 дней деньги, и если да, то сколько?» Третий подпункт вопроса имеет расшифровку: «На билеты: в театр, цирк, кино, на концерты, в парки культуры и другие развлекательные мероприятия». При положительном ответе респонденты сообщают затем, какая сумма (в рублях) была потрачена ими на эти цели. Получаемые на этой основе показатели обладают рядом особенностей, которые необходимо учитывать. Во-первых, они строятся не на уровне индивидов, а на уровне целых домохозяйств. Во-вторых, они являются максимально агрегированными (относятся ко всему набору культурных благ). В-третьих, они охватывают достаточно короткий - месячный - интервал времени. Это серьезное ограничение, поскольку потребление культурных благ протекает обычно достаточно дискретно, с большими перерывами во времени.

Дополнительным источником информации, как отмечалось выше, выступало «Комплексное наблюдение условий жизни населения» (КОУЖ) Росстата, охватывающее взрослых индивидов в возрасте 15 лет и старше. Его анкета включает специальный раздел, посвященный использованию свободного времени и отдыху. Ключевой для нас вопрос формулируется так: «Как часто в течение последних 12 месяцев Вы были в... ?» с последующим перечислением нескольких альтернативных форм проведения досуга. К потреблению культурных благ можно отнести четыре пункта из этого перечня - посещения кино, театров, концертов, музеев и художественных выставок. Частота посещений по каждой позиции оценивается с помощью вариантов ответа «регулярно» или «один или несколько раз», что позволяет отделять постоянную публику от разовой.

Исходя из этих данных, мы конструируем два показателя: 1) коэффициент активности (доля в выборке КОУЖ зрителей / слушателей каждого вида искусства); 2) коэффициент регулярности (доля в аудитории каждого вида искусства его постоянных зрителей/слушателей). Помимо частных, мы рассчитываем также общие коэффициенты активности и регулярности, показывающие, какова суммарная доля всех потребителей культурных благ, а также какова суммарная доля всех постоянных потребителей этих благ.

По сравнению с дизайном РМЭЗ-ВШЭ дизайн КОУЖ обладает как плюсами, так и минусами. Во-первых, информация о спросе на культурных блага собирается в нем по индивидам, а не домохозяйствам. Во-вторых, период обследования является более протяженным год, а не месяц. В-третьих, выделяются четыре группы культурных благ (кино, театры, концерты и музеи). В-четвертых, разовые зрители/слушатели отделяются от постоянных. В то же время КОУЖ не содержит информации о расходах, направляемых индивидами на культурные цели.

\section{Масштабы и динамика}

\section{РМЭЗ-ВШЭ}

Динамика ключевых характеристик потребления культурных благ, по данным РМЭЗ-ВШЭ, представлена на рис. 1. Для доли потребителей подобных благ мы наблюдаем отчетливый повышательный тренд: с примерно $10 \%$ от всех обследуемых домохозяйств в начале 2000-х годов до примерно $20 \%$ в настоящее время. Для 2009-2018 гг. она примерно в полтора раза выше, чем для 2000-2008 гг.: 18,4 против 12,4\%. Напротив, доля расходов на культурные блага демонстрирует слабый понижательный тренд: с 2,6\% в начале предыдущего десятилетия до 2,3\% в настоящее время.

К сожалению, месячные данные занижают действительную долю домохозяйств, потребляющих культурные блага на протяжении всего года. Масштаб занижения удается 


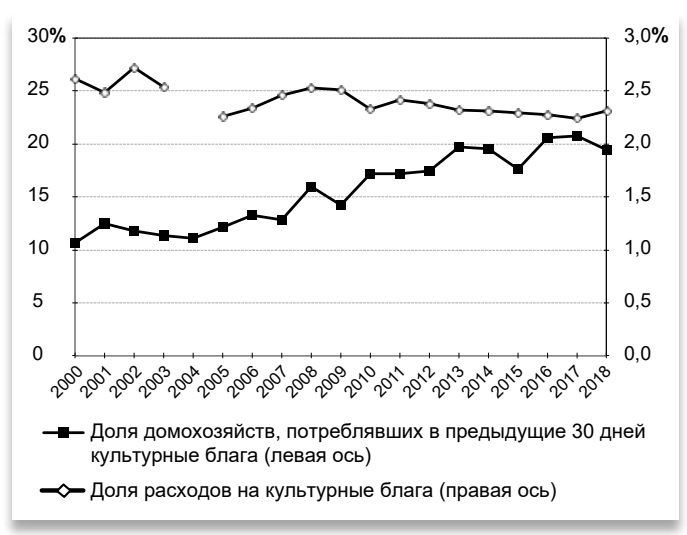

Pис. 1

Динамика доли потребителей культурных благ и доли расходов на эти блага (2000-2018 ге.), \%

Источник: РМЭЗ-ВШЭ.

оценить с помощью данных РМЭЗ-ВШЭ об интенсивности ротации потребителей таких благ от года к году. Как видно из данных, представленных в табл. 1, до кризиса 2008-2009 гг. стойкими потребителями культурных благ, приобретавшими их в обследуемые месяцы два года подряд, были менее $4 \%$ домохозяйств. Для посткризисного периода аналогичная оценка значительно выше $-8,4 \%$.

Отталкиваясь от әтих цифр, можно перейти от месячных оценок к годовым. Так, например, в 2018 г. доля потребителей культурных благ приближалась к $20 \%$, причем соотношение между теми, кто предъявлял на них спрос и в этом, и в предыдущем году, и теми, кто предъявлял его только в предыдущем году, но не предъявлял в этом, выглядело как 0,48 : 0,52. Взяв это соотношение за точку отсчета, можно попытаться оценить пул потребителей культурных благ на протяжении всего 2018 г.
Предположим, что потребление культурных благ не подвержено сезонным колебаниям и что доля стойких потребителей не зависит от временной дистанции, отделяющей один месяц от другого. (Это означает, что если, например, доля домохозяйств, предъявлявших спрос на культурные блага как в октябре 2017 г., так и в октябре 2018 г., составляла $48 \%$ их общего числа в октябре 2018 г. (см. выше), то зона пересечения между январем 2018 г. и февралем 2018 г., между январем 2018 г. и мартом 2018 г. и т.д. также будет равна 48\%.) При этих предположениях доля потребителей на протяжении первого полугодия 2018 г. составит $41 \%\left(20 \%+20 \% \times 0,52+20 \% \times 0,52^{2}+20 \% \times 0,52^{3}+\right.$ $\left.+20 \% \times 0,52^{4}+20 \% \times 0,52^{5}\right)$. Если допустить, что в каждый из оставшихся шести месяцев доля уникальных потребителей (тех, кто предъявлял спрос только в данном месяце, но не предъявлял его ни в каком другом) равнялась $1 \%$, то тогда потребителями культурных благ на протяжении всего 2018 г. окажутся около $50 \%$ российских домохозяйств.

\section{КОУЖ}

Более дифференцированная картина вырисовывается из данных КОУЖ. Основные результаты представлены в табл. 2, где в первой строке приводятся общий и четыре частных коэффициента активности, а в последней колонке коэффициенты регулярности отдельно по каждому виду искусства и по всем ним вместе. Остальные ячейки характеризуют сочетаемость разных видов культурных благ друг с другом (например, какая часть кинозрителей, помимо посещения кинотеатров, посещала также театры и т.д.). Цифры по диагонали, выделенные жирным шрифтом, пока-

таблица 1

Характеристики ротации потребителей культурных благ, усредненные оценки за 2000-2018 гг., \%

\begin{tabular}{|c|c|c|c|c|c|c|}
\hline \multirow{2}{*}{ Текущий год } & \multicolumn{9}{|c|}{ В предыдущем году } \\
\cline { 2 - 7 } & $\begin{array}{c}\text { не потре- } \\
\text { бляли }\end{array}$ & $\begin{array}{c}\text { потре- } \\
\text { бляли }\end{array}$ & $\begin{array}{c}\text { не потре- } \\
\text { бляли }\end{array}$ & $\begin{array}{c}\text { потре- } \\
\text { бляли }\end{array}$ & $\begin{array}{c}\text { не потре- } \\
\text { бляли }\end{array}$ & $\begin{array}{c}\text { потре- } \\
\text { бляли }\end{array}$ \\
\hline \hline Не потребляли & 81,8 & 6,7 & 72,1 & 9,8 & 77,1 & 8,2 \\
\hline Потребляли & 7,8 & 3,8 & 9,7 & 8,4 & 8,7 & 6,0 \\
\hline
\end{tabular}

Источник: РМЭЗ-ВШЭ. 
Таблица 2

Коэффициенты активности и регулярности, усредненные оценки за 2011-2018 гг., \%

\begin{tabular}{|c|c|c|c|c|c|c|}
\hline \multirow{2}{*}{$\begin{array}{c}\text { Виды } \\
\text { искусства }\end{array}$} & \multicolumn{5}{|c|}{ Коэффициент активности } & \multirow{2}{*}{$\begin{array}{l}\text { Коэффициенл } \\
\text { регулярности }\end{array}$} \\
\hline & общий & кино & театр & концерты & музеи & \\
\hline Bce & $\overline{50,3}$ & 34,9 & 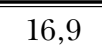 & 24,8 & 13,2 & $\overline{19,7}$ \\
\hline Кино & - & 42,4 & 32,5 & 39,3 & 23,9 & 21,4 \\
\hline Театр & - & 67,0 & 10,6 & 57,4 & 42,2 & 11,0 \\
\hline Концерты & - & 55,1 & 39,1 & 28,4 & 29,6 & 8,8 \\
\hline Музеи & - & 63,3 & 54,3 & 55,9 & 12,1 & 11,5 \\
\hline
\end{tabular}

Источник: расчеты авторов па данным КОУЖ Росстата.

зывают, сколько в аудитории каждого вида искусства насчитывалось однолюбов - тех, кто интересовался только им и больше никакими другими.

Согласно этим оценкам на протяжении 2011-2018 гг. свыше половины всех россиян посещали в течение года кино, театры, концерты или музеи. Поразительно, но этот результат почти идеально согласуется с приближенной оценкой, полученной нами исходя из месячных данных РМЭЗ-ВШЭ. Как нетрудно догадаться, наибольшей популярностью пользуется кино - коэффициент активности около 35\%. За ним идут концерты (25\%), театры (17\%) и, наконец, музеи (13\%). Однако если рассматривать постоянную часть аудитории, то ранжирование оказывается во многом иным. Хотя и в этом случае лидером остается кино (свыше 20\% всех кинозрителей смотрят фильмы регулярно), но второе место зани-

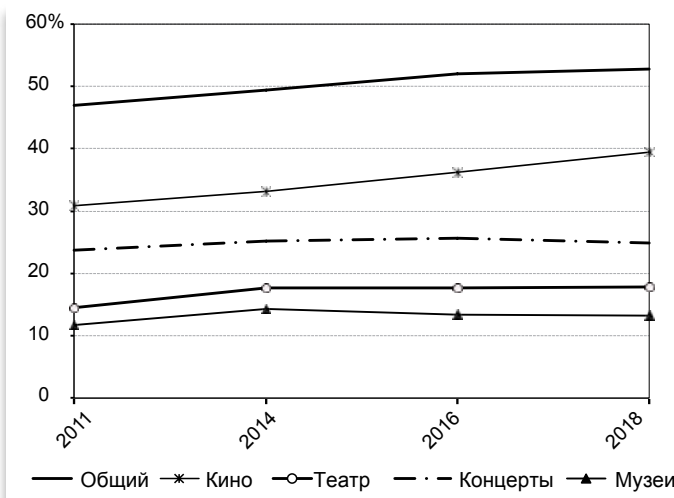

Puc. 2

Динамика коэффичиентов активности, 2011-2018 22., \%

Источник: расчеты авторов по данным КОУЖ Росстата. мают музеи (около 12\%), третье - театры (11\%) и лишь четвертое - концерты (менее 9\%).

Однолюбов среди посетителей кино и концертов насчитывается в несколько раз больше, чем среди посетителей театров и музеев: 28-42\% против 11-12\%. Это наглядное подтверждение того, что тех, кто ходит в театры или музеи, отличает намного большая широта вкусов и интересов по сравнению с теми, кто ходит в кино или на концерты.

График на рис. 2 свидетельствует, что на протяжении рассматриваемого периода коэффициенты активности оставались по большей части стабильными. Единственное исключение - расширение киноаудитории (почти на 10 п.п.), что повлекло за собой смещение вверх (на 6 п.п.) также и общего коэффициента активности.

\section{Потребление культурных благ и дифференциация доходов РМЭЗ-ВШЭ}

Табл. 3 и 4, построенные на усредненных данных РМЭЗ-ВШЭ за 2000-2018 гг., демонстрируют отчетливую закономерность: чем выше душевой доход домохозяйств, тем выше вероятность потребления ими культурных благ. В нижнем дециле такие блага потребляет лишь каждое десятое-двадцатое домохозяйство, тогда как в верхнем - каждое третьечетвертое. Разрыв, таким образом, достигает 3-7 раз, причем в 2009-2018 гг. он заметно увеличился по сравнению с 2000-2008 гг.

В среднем один шаг вверх по шкале душевого дохода сопровождается увеличением доли домохозяйств-потребителей культурных благ 
примерно на 2-3 п.п. Интересно отметить, что использование шкалы эквивалентности увеличивает глубину неравенства, поскольку при такой корректировке доля домохозяйствпотребителей в нижнем дециле снижается (на 2-3 п.п.), а в верхнем, напротив, возрастает (на 5-6 п.п.).

Обратная ситуация наблюдается для доли расходов на культурные блага (табл. 3). У домохозяйств из двух нижних децилей она оказывается в полтора-два раза выше, чем у остальных домохозяйств. Причина - крайне низкие доходы, из-за чего даже относительно скромные расходы на культурные цели способны пробивать в бюджете бедных домохозяйств заметную брешь.

Мы можем взглянуть на проблему в обратной перспективе, сопоставив доходы домохозяйств, потреблявших и не потреблявших культурные блага. Как показывает рис. 3, среднедушевой доход домохозяйств-потребителей устойчиво превышал среднедушевой доход

\section{Таблица 3}

Доли потребителей культурных благ по децилям душевого дохода домохозяйств, усредненные оценки за 2000-2018 гг., \%

\begin{tabular}{|c|c|c|c|c|c|c|}
\hline \multirow{2}{*}{ Децили } & \multicolumn{2}{|c|}{ Без шкалы эквивалентности } & \multicolumn{3}{c|}{ Со шкалой эквивалентности } \\
\cline { 2 - 7 } & $2000-2008$ гг. & 2009-2018 гг. & 2000-2018 гг. & 2000-2008 гг. & 2009-2018 гг. & 2000-2018 гг. \\
\hline \hline 1 & 6,4 & 10,4 & 8,5 & 4,6 & 6,6 & 5,7 \\
\hline 2 & 7,5 & 14,2 & 11,0 & 4,3 & 7,5 & 6,0 \\
\hline 3 & 7,2 & 16,0 & 11,8 & 4,9 & 10,2 & 7,7 \\
\hline 4 & 8,6 & 14,7 & 11,8 & 6,6 & 13,4 & 10,1 \\
\hline 5 & 9,1 & 16,6 & 13,0 & 10,0 & 15,4 & 12,8 \\
\hline 6 & 11,4 & 17,3 & 14,5 & 13,1 & 19,7 & 16,6 \\
\hline 7 & 14,7 & 19,1 & 17,0 & 16,3 & 22,1 & 19,3 \\
\hline 8 & 16,9 & 21,2 & 19,1 & 18,2 & 25,9 & 22,3 \\
\hline 9 & 18,7 & 24,6 & 21,8 & 20,1 & 28,5 & 24,5 \\
\hline 10 & 23,2 & 29,6 & 26,6 & 25,9 & 34,4 & 30,4 \\
\hline
\end{tabular}

Источник: РМЭЗ-ВШЭ.

Таблица 4

Доли расходов на культурные блага по децилям душевого дохода домохозяйств, усредненные оценки за 2000-2018 гг., \%

\begin{tabular}{|c|c|c|c|c|c|c|}
\hline \multirow{2}{*}{ Децили } & \multicolumn{3}{|c|}{ Без шкалы әквивалентности } & \multicolumn{3}{|c|}{ Со шкалой әквивалентности } \\
\hline & 2000-2008 гг. & 2009-2018 гг. & 2000-2018 гг. & 2000-2008 гг. & 2009-2018 гг. & 2000-2018 гг. \\
\hline 1 & 4,9 & 3,4 & 4,0 & 5,6 & 5,1 & 5,3 \\
\hline 2 & 3,2 & 2,7 & 2,9 & 5,0 & 3,3 & 4,1 \\
\hline 3 & 2,4 & 2,1 & 2,3 & 3,0 & 2,7 & 2,8 \\
\hline 4 & 2,6 & 2,2 & 2,4 & 2,9 & 2,4 & 2,7 \\
\hline 5 & 2,3 & 2,3 & 2,3 & 2,9 & 2,4 & 2,6 \\
\hline 6 & 2,4 & 2,1 & 2,2 & 2,5 & 2,3 & 2,4 \\
\hline 7 & 2,6 & 2,4 & 2,4 & 2,5 & 2,1 & 2,3 \\
\hline 8 & 2,1 & 2,3 & 2,2 & 2,2 & 2,2 & 2,2 \\
\hline 9 & 2,5 & 2,3 & 2,4 & 2,2 & 2,1 & 2,2 \\
\hline 10 & 2,2 & 2,3 & 2,2 & 1,8 & 1,9 & 1,9 \\
\hline
\end{tabular}

Источник: РМЭЗ-ВШЭ. 


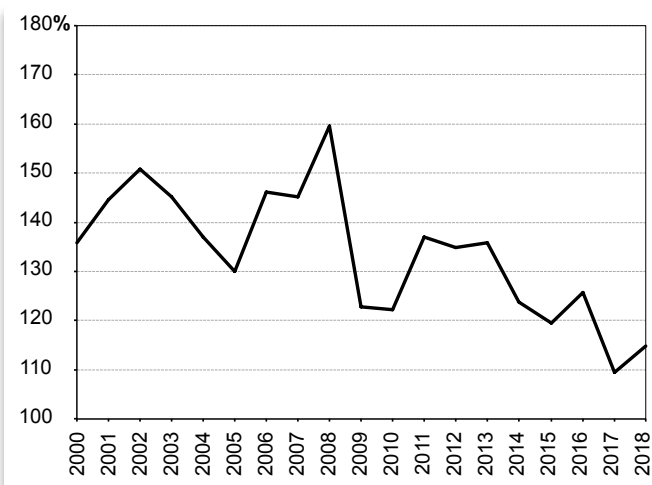

Рис. 3

Соотношение между среднедушевыми доходами домохозяйств, потреблявиих и не потреблявиих культурные блага, 2000-2018 ге., \%

Источник: РМЭЗ-ВШЭ.

домохозяйств-непотребителей. В среднем разрыв составлял треть. Он был существенно больше в 2000-2008 гг., когда достигал 30-60\%, чем в 2009-2018 гг., когда колебался в диапазоне 10-30\%. Это сжатие скорее всего было связано с переходом большого числа домохозяйств со сравнительно невысокими доходами из группы непотребителей в группу потребителей культурных благ, что, в свою очередь, было вызвано быстрым общим ростом доходов населения в рассматриваемый период.

\section{КОУЖ}

По данным КОУЖ, вероятность потребления любых культурных благ монотонно возрастает по мере перемещения от нижних децилей по душевому доходу к верхним (табл. 5). Так, в нижнем дециле общий коэффициент активности не дотягивает до $33 \%$, тогда как в верхнем он достигает $73 \%$.

Среди индивидов из верхнего дециля примерно каждый второй в течение года бывает в кино, каждый третий - в театре или на концертах и примерно каждый четвертый в музеях. Аналогичные оценки для индивидов из нижнего дециля составляют около $20 \%$ в случае кино и концертов и менее $10 \%$ в случае театра и музеев. Больший относительный разрыв наблюдается для элитарных видов искусства - театра (7 раз) и музеев (5 раз). Для массовых, кино и концертов, он существенно меньше (2-3 раза). По-видимому, по мере роста душевого дохода спрос на элитарные виды искусства повышается активнее, чем на массовые. Увеличивается также и доля постоянной публики: в верхнем дециле ее насчитывается в два-три раза больше, чем в нижнем.

Как и в случае РМЭЗ-ВШЭ, мы можем произвести обратную группировку, сопоставив уровни дохода у групп посетителей и непосетителей, как это сделано на рис. 4.

Таблица 5

Коэффициенты активности и регулярности по децилям душевого дохода, усредненные оценки за 2011-2018 гг., \%

\begin{tabular}{|c|c|c|c|c|c|c|c|c|c|c|}
\hline \multirow{2}{*}{ Децили } & \multicolumn{4}{|c|}{ Коэффициент активности } & \multicolumn{5}{c|}{ Коэффициент регулярности } \\
\cline { 2 - 11 } & общий & кино & театр & концерты & музеи & общий & кино & театр & концерты & музеи \\
\hline \hline 1 & 33,7 & 19,8 & 5,2 & 19,3 & 5,5 & 10,5 & 11,0 & 7,2 & 7,6 & 5,7 \\
\hline 2 & 37,9 & 24,0 & 6,8 & 20,4 & 6,7 & 11,2 & 11,3 & 6,1 & 7,8 & 6,0 \\
\hline 3 & 38,5 & 23,8 & 8,2 & 21,3 & 7,5 & 12,1 & 12,5 & 5,8 & 8,1 & 5,6 \\
\hline 4 & 40,3 & 24,9 & 9,9 & 22,0 & 8,7 & 13,5 & 14,2 & 7,8 & 8,4 & 6,8 \\
\hline 5 & 35,6 & 19,0 & 10,2 & 21,3 & 8,4 & 14,1 & 14,6 & 8,1 & 9,2 & 8,1 \\
\hline 6 & 48,8 & 33,6 & 14,5 & 25,2 & 11,7 & 15,6 & 16,8 & 8,9 & 7,7 & 7,6 \\
\hline 7 & 43,8 & 26,2 & 15,0 & 24,2 & 11,1 & 16,0 & 18,1 & 8,3 & 8,6 & 9,1 \\
\hline 8 & 55,2 & 38,0 & 20,2 & 27,8 & 15,7 & 18,9 & 20,7 & 9,3 & 7,8 & 10,6 \\
\hline 9 & 64,9 & 47,2 & 26,6 & 31,7 & 20,7 & 23,8 & 25,0 & 11,4 & 9,2 & 13,3 \\
\hline 10 & 73,1 & 54,6 & 34,9 & 36,7 & 28,7 & 28,0 & 28,6 & 14,6 & 11,5 & 16,8 \\
\hline
\end{tabular}

Истоиник: расчеты авторов па данным КОУж Росстата. 


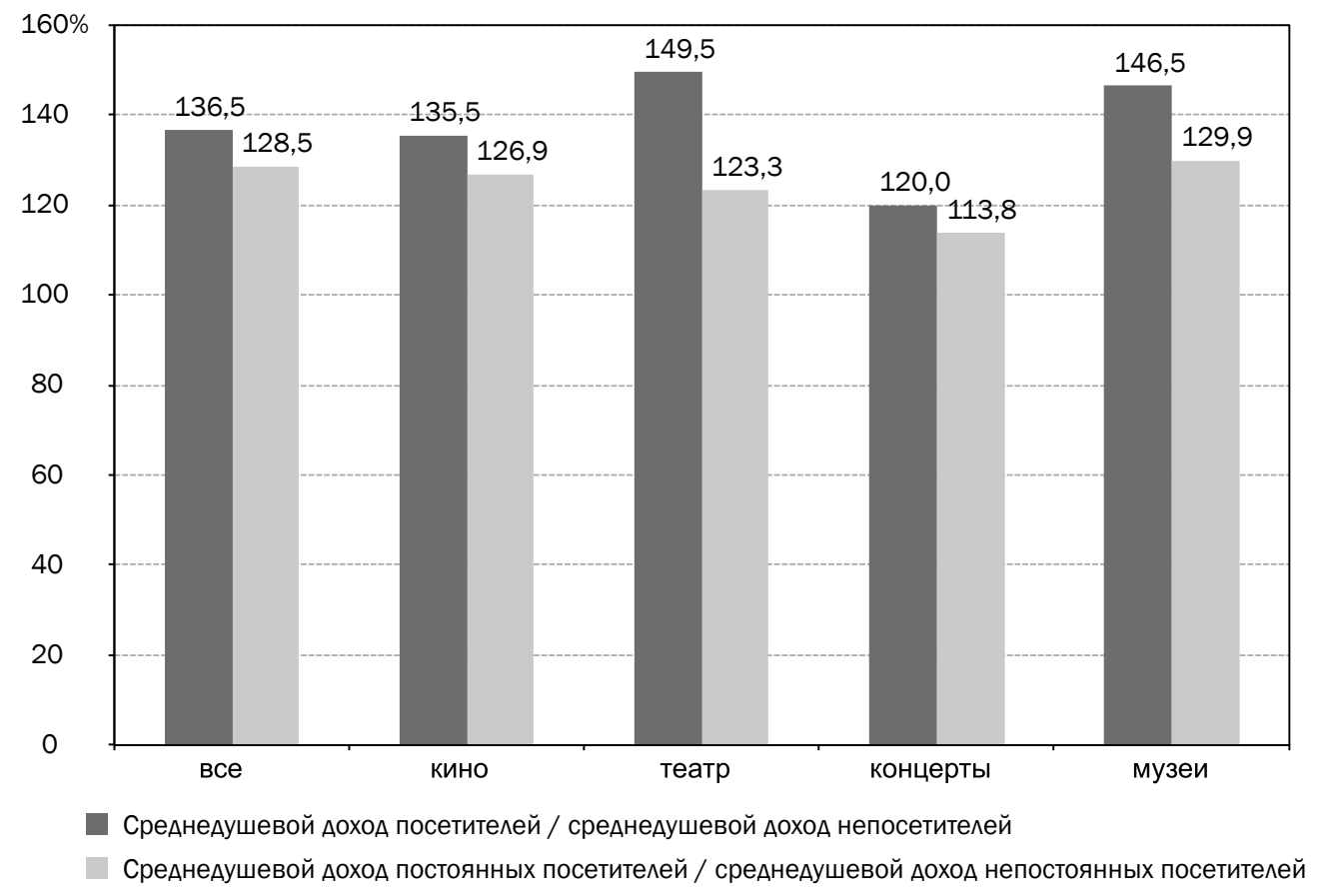

Puc. 4

Соотношение между среднедушевыми доходами посетителей и непосетителей и среднедушевъми доходами постоянных и непостоянных посетителей, усредненные оченки за 2011-2018 г2., \% Источник: расчеты авторов по данным КОУж Росстата.

Отрыв первых от вторых достигает в среднем $37 \%$. Максимальным он оказывается для театра - 50\%, минимальным для концертов $-20 \%$. Иными словами, театралы имеют в среднем в полтора раза больший доход, чем нетеатралы! Аналогичный разрыв, правда меньшего порядка, наблюдается между постоянными и разовыми зрителями/слушателями: средний доход первых, как показывает график на рис. 4, на 25-30\% превосходит средний доход вторых.

Контрасты велики и устойчивы: посетители кино, театров, концертов и музеев в среднем намного богаче непосетителей, а те, кто посещает их регулярно, в среднем намного богаче тех, кто делает это эпизодически. В результате, если сравнить среднедушевые доходы двух крайних групп, то окажется, что у постоянных зрителей/слушателей они примерно в полтора-два раза выше, чем у незрителей/неслушателей!

\section{Заключение}

Наши оценки дают достаточно полную картину потребления культурных благ в российском контексте. В настоящее время их потребляет примерно каждое второе домохозяйство и примерно каждый второй индивид. Наибольшей популярностью пользуется кино, затем идут концерты, а после них уже театр и музеи. Постоянная аудитория составляет примерно пятую часть общего числа посетителей. Доля расходов, направляемых на эти цели, достигает $2,5 \%$ месячного бюджета домохозяйств.

Много это или мало? Любые межстрановые сравнения оказываются здесь приблизительными, так как найти в исследованиях по другим странам оценки, которые были бы полностью аналогичны оценкам по России, непросто. Так, в Германии (2006 г.) в течение года $26 \%$ домохозяйств посещали кино и около $10 \%$ - театры, что, по-видимому, меньше, чем 
в России, но 28\% - музеи, что значительно больше. На это они тратили примерно 2\% своего годового бюджета (Borgonovi, 2004). В Испании (2004 г.) 14\%, а в США (2002 г.) примерно $13 \%$ взрослых индивидов приобретали в течение предыдущего месяца какие-либо культурные блага, что также, по-видимому, несколько меньше, чем в России (Pawlowski, Breuer, 2012; Muñiz et al., 2014). В целом российская ситуация достаточно близка к ситуации в развитых странах, и это - при куда более низком душевом ВВП.

В российских условиях мы наблюдаем четкую взаимосвязь: чем экономически успешнее домохозяйства или индивиды, тем активнее они в сфере потребления культурных благ. Естественно, верно и обратное: доходы у культурно активных домохозяйств и индивидов значительно выше (примерно на треть по обоим источникам), чем у культурно пассивных. Самые процветающие группы ходят в кино в два с половиной раза чаще, в театры - в семь раз чаще, на концерты - в два раза чаще и в музеи - в шесть раз чаще, чем самые бедствующие.

В принципе положительная взаимосвязь между доходом и потреблением культурных благ фиксируется для всех стран, по которым проводились соответствующие измерения. Но в российском случае она, похоже, намного сильнее и устойчивее. Если это так, то существует достаточно тривиальный, но әффективный способ, как можно было бы стимулировать спрос населения на культурные блага: это - ускорение темпов экономического роста.

\section{ЛИТЕРАТУРА / REFERENCES}

Автономов Ю.В. (2013). Результаты эмпирических исследований спроса на исполнительское искусство и объекты культурного наследия. В кн.: «Экономика культуры: новый ракурс старых проблем». А.Я. Рубинштейн, В.Ю. Музычук (ред.). М.: ИЭ РАН. С. 179-230. [Avtonomov Yu.V. (2013). The results of empirical research on the demand for performing arts and cultural heritage. In: The econom ics of culture: A new perspective of old problems. A.Ya. Rubinstein, V.Yu. Muzychuk (eds.). Moscow: IE RAS, 179-230 (in Russian).]

Бузанакова A.P., Ожегов Е.M. (2016). О различных подходах к идентификации предпочтений зрителей театральных постановок // Экономический анализ: теория и практика. № 10. С. 168-182. [Buzanakova A.R., Ozhegov E.M. (2016). On different approaches to identifying the preferences of theatergoer. Economic Analy sis: Theory and Practice, 10, 168-182 (in Russian).]

Borgonovi F. (2004). Performing arts attendance: An economic approach. Applied Economics, 36, 26, 1871-1885.

Muñiz C., Rodriguez P., Suarez M. (2014). Sports and cultural habits by gender: An application using count data models. Economic Modelling, 36, January, 288-297.

Pawlowski T., Breuer C. (2012). Expenditure elasticities of the demand for leisure services. Applied Economics, 44, 17, 3461-3477.

Yoon S., Heo S. (2015). Empirical studies of the demand for cultural services in South Korea. Proceedings of the IRES 14th International Conference, Paris, France.

Поступила в редакиию 23.04.2020

Received 23.04.2020 


\title{
R.I. Kapeliushnikov
}

Primakov National Research Institute of World Economy and International Relations, RAS; Centre for Labour Market Studies, National Research University "Higher School of Economics"; Moscow, Russia

\section{A.V. Sharunina \\ Centre for Labour Market Studies, National Research University "Higher School of Economics"; Moscow, Russia \\ Consumption of cultural goods in Russia: What household surveys tell us?}

\begin{abstract}
The paper examines dynamics in consumption of cultural goods in Russia. The sources of empirical data are the Russian Longitudinal Monitoring Survey (RLMS-HSE) for 2000-2018 and Rosstat's Complex Living Conditions Survey (CLCS) for 2011-2018. The analysis indicates that now approximately every second household and approximately every second adult individual consumes some cultural goods during the year. A regular audience is approximately one fifth of the total. The share of expenses on cultural goods reaches $2.5 \%$ of average monthly household budget. With the rapid income growth in 2000-2018 demand for cultural goods has been steadily increasing. There is a visible empirical regularity: the higher the income of households or individuals, the more active they are culturally. There appears to be a fairly banal, but effective practical way to stimulate demand for cultural goods in Russia: an acceleration of economic growth.
\end{abstract}

Keywords: consumption, cultural goods, income, Russia, survey data.

JEL Classification: D12, D31, Z11, Z18.

DOI: $10.31737 / 2221-2264-2020-47-3-11$

\section{И.В. Абанкина \\ Институт образования, НИУ ВШЭ, Москва \\ T.В. Абанкина \\ Институт управления государственными ресурсами, НИУ ВШЭ, Москва \\ Равенство прав vs равенство возможностей в сфере высшего образования}

Журнал НЭА №3 (47), 2020 c. 205-214

Аннотация. В статье анализируется сложившаяся дифференциация в потреблении опекаемых благ в сфере высшего образования. Обосновывается, что сложилась глубокая дифференциация доступности высшего образования по направлениям подготовки в зависимости от доходов семей. Высокий уровень школьной подготовки по естественно-научным дисциплинам и информатике и возможности семей оплачивать репетиторов обеспечивают абитуриентам более высокие шансы обучаться за счет бюджетных средств по сравнению с абитуриентами из семей с низкими доходами. Образование в секторе творческих профессий и дизайна прямо зависит от уровня доходов семей и развивается крайне неравномерно как по регионам России, так и по направлениям подготовки. Нынешние условия пандемии коронавируса и грядущего экономического кризиса до предела обострили проблему доступности высшего образования для семей с низкими доходами. Перспективной моделью сохранения доступности высшего образования для абитуриентов из семей с низкими доходами может стать интеграция финансовых инструментов, напрямую обеспечивающих поддержку как учебных заведений, так и студентов и их семей за счет бюджетных средств. Персонифицированное финансирование допускает участие самих студентов в распоряжении частью опекаемых благ через образовательные бюджетные сертификаты.

Ключевые слова: доступность высшего образования, опекаемые блага, финансирование высшего образования, платное образование.

Классификация JEL: H52, I22, I23.

DOI: $10.31737 / 2221-2264-2020-47-3-12$ 